\title{
Bazı Biyoinsektisitlerin Myzus persicae (Sulzer) (Hemiptera: Aphididae)'ye Etkileri
}

\author{
Gülsüm KURŞUNCU ŞAHİN1® ${ }^{\circledR}$, İsmail KARACA*2@ \\ 1,2Isparta Uygulamalı Bilimler Üniversitesi, Tarım Bilimleri ve Teknolojileri Fakültesi, Bitki Koruma Bölümü, \\ 32260, Isparta, Türkiye
}

(Alınış / Received: 10.12.2018, Kabul / Accepted: 05.08.2019, Online Yayınlanma / Published Online: 30.08.2019)

Anahtar Kelimeler Biyolojik mücadele, Şeftali yeşil yaprakbiti, Biyolojik preparatlar
Özet: $\mathrm{Bu}$ çalışmada 4 farklı biyopestisit (Bio-Catch ${ }^{\circledR}$, Bio-Magic ${ }^{\circledR}$, Nostalgist ${ }^{\circledR}$ ve Priority ${ }^{\circledR}$ ) ile bitkisel ekstraktlı bir preparat (Nimbedicine) ve karşılaștırma ilacı olarak Chlorpyrifos-ethyl etken maddeli preparat laboratuvar koşullarında Myzus persicae (Sulzer) (Hemiptera: Aphididae)'ye püskürtme şeklinde firmaların önerdiği dozlarda uygulanmıştır. Çalışmalar Süleyman Demirel Üniversitesi, Ziraat Fakültesi, Bitki Koruma Bölümü, Biyolojik Mücadele Araștırma ve Uygulama Laboratuvarı'nda petri ve saksı denemeleri şeklinde yürütülmüştür. Preparatlar petriye yerleştirilmiş biber yaprakları üzerine ve saksılardaki biber bitkilerine püskürtme şeklinde uygulanmıştır. Uygulamalardan 10 dakika sonra her bir petriye 10 birey, her bir saksıdaki bitkinin bir yaprağına 5 birey olmak üzere toplamda 3 yaprağa 15 birey bulaştırılmıştır. Petri denemeleri 10, saksı denemeleri 4 tekerrürlü olarak kurulmuştur. Uygulamalardan sonra sayımlar petri denemelerinde 1., 3., 5. ve 7. günlerde, saksı denemelerinde sadece 7. günde yapılmıştır. Sayımlarda canlı ve ölü bireyler kayıt altına alınmıştır. Çalışma sonucunda, petri denemelerinde 7. günün sonunda Bio-Catch ${ }^{\circledR}$, Bio-Magic $^{\circledR}$, Nostalgist $^{\circledR}$, Priority ${ }^{\circledR}$, Nimbedicine ve Chlorpyrifos-ethyl'in M. persicae'ye Abbott'a göre etkileri sirasıyla \%39, \%35, \%47, \%39, \%68 ve \%100 olarak bulunmuştur. Saksı denemelerinde ise bu etki yine 7. günde sırasıly $\% 44.44, \% 42.59, \% 53.70, \% 37.04, \% 68.52$ ve \%100.00 olarak saptanmıştır. Sonuç olarak, gerek petri denemelerinde gerekse saksı denemelerinde M. persicae’ye en etkili Chlorpyrifos-ethyl bulunmuş, bunu Nimbedicine izlemiştir. Biyoinsektisitlerin etkileri ise birbirine yakın bulunmuştur.

\section{Effects of Some Bioinsecticides on Myzus persicae}

Keywords

Biological control, Biological preparats, Green peach aphid

\begin{abstract}
In this study, effects of four different biopesticides (Priority ${ }^{\circledR}$, Nimbecidine ${ }^{\circledR}$, Nostalgist ${ }^{\circledR}$, Bio-Magic ${ }^{\circledR}$ ve Bio-Catch ${ }^{\circledR}$ ) and a plant extract (Nimbedicine), and also for comparison Chlorpyrifos-ethyl, on Myzus persicae (Sulzer) (Hemiptera: Aphididae) were investigated by spraying method under the loboratory conditions. Experiments were performed with two different methods (petri dishes and pots) in Süleyman Demirel University, Agricultual Faculty, Biological Control Research and Applying Laboratory of Plant Protection Department. The preparats were applied as spray in pepper leaves placed in petri dishes and pepper plants in pots. After 10 minutes, 10 individuals were transferred into each petri dish and 5 aphids were placed into one leaf of each plant than 15 aphids were infested to 3 leaves of the each plant. Petri dishes and pots experiments were established with 10 and 4 replicates, respectively. After the applications, the counts were made on the 1st, 3rd, 5th and 7th days in the petri dishes and only on the 7th day in the pots. Live and dead individuals were recorded. As a result of the study, the effects to M. persicae of Bio-Catch ${ }^{\circledR}$, Bio-Magic $^{\circledR}$, Nostalgist ${ }^{\circledR}$, Priority ${ }^{\circledR}$, Nimbedicine and Chlorpyrifos-ethyl according to Abbott in the petri dishes experiments were $39 \%, 35 \%, 47 \%, 39 \%, 68 \%$ and $100 \%$, respectively on day 7 th. In pot experiments, this effect is $\% 44.44, \% 42.59, \% 53.70, \% 37.04, \% 68.52$ ve $\% 100.00$ on day 7th. As a result, the most effective Chlorpyrifos-ethyl was found on M. persicae in both petri dishes and pot experiments, followed by Nimbedicine. The effects of bioinsecticides were similar.
\end{abstract}




\section{Giriş}

Yaprakbitleri olarak bilinen Aphidoidea tür sayısı ve yoğunluk açısından önemli bir gruptur. Yaprakbitlerinin dünyada 599 cinse ait yaklaşık 4700 türü olduğu bilinmektedir [1]. Ülkemizde de Aphidoidea üst familyasına ait türleri belirlemek amacıyla pek çok çalışma yapılmıştır [2 - 19].

Dünyada yapılan çalışmalar hem kültür bitkilerinde hem de yabani otsu bitkiler üzerinde beslenmekte olan yaprakbitlerini içermektedir. $\mathrm{Bu}$ çalıșmalar sonucunda yaprakbiti tür sayısının 541 kadar olduğu saptanmıştır [20].

Söz konusu bu yaprakbiti türleri içerisinde yer alan ve oldukça fazla sayıda konukçuya sahip olan Myzus persicae (Sulzer) (Hemiptera: Aphididae) dikkat çekmektedir. İsrail' de bu zararlının 34 familyaya bağlı 80'den fazla bitki türünde beslendiği belirtilmiștir [21].

Primer konukçu olarak seçtiği Prunus persica (L.) Batsch (Rosaceae) ve diğer Prunus türleri ile çok sayıda sekonder konukçusu üzerinde yaşamını sürdürmekte, ılıman bölgelerde ve sera koşullarında parthenogenetik vivipar çoğalmayla yıl boyu yaşamına devam etmektedir. Konukçularının yeni gelişen dokularında, yaprakların altlarında ve yaşlı yapraklarda yoğun koloniler oluşturarak kıvrılmalar meydana getirmektedir. $\mathrm{Bu}$ türün persistent ve nonpersistent yolla 100 'den fazla bitki virüs hastalığını nakledebildiği belirtilmektedir. Polifag bir tür olan M. persiace'nin persistent yolla naklettiği virüslere tütün yaprak bükülme virüsü, domates sarı ağ virüsü, nonpersistent yolla naklettiği virüslere ise patates aucuba mozaik virüsü, patates A virüsü, patates $Y$ virüsü ve tütün solgunluk virüsünün örnek olarak verilebileceği bildirmişlerdir [22].

Asya orjinli olduğu düşünülen bu türün kozmopolit bir yayılış gösterdiği belirtilmiştir [23]. Avrupa, İspanya, Yunanistan, Slovenya, Afrika, Kuzey Amerika, Arjantin, Venezuella, Asya, Güney ve Batı Avustralya, Tasmanya, Yeni Zelanda, Kuzey Kıbrıs Türk Cumhuriyeti, Mısır, Tunus, Pakistan, Irak, Israil ve Lübnan' da bulundugu bildirilmistir [3]; [10]; [24]; [25]; [26]. M. persicae'ye ait ülkemizdeki ilk kayıt 1938 yllında Ankara'da Spinacia oleracea L. (Spinacia) üzerinden yapılmıştır [3].

Söz konusu zararlıya karşı savaşımda genellikle tarım ilaçları kullanılmaktadır. Bilindiği gibi kimyasal savaş insan sağlığı, doğal çevre ve doğal denge üzerinde olumsuz etkiler yaratmaktadır. Ayrıca zararlının kısa zamanda ve çok sayıda döl vermesi nedeni ile de bir çok kimyasala karşı direnç kazandığı bildirilmiştir [27 - 29]. Bu nedenle zararlılara karşı alternatif mücadele yöntemleri üzerindeki çalışmalar özellikle de biyolojik mücadele çalışmaları son zamanlarda ağırlık kazanmıştır [30, 31].
Bu çalışmanın amacı yaprakbitleri içinde yer alan ve Türkçe'de Şeftali yeşil yaprakbiti olarak bilinen $M$. persicae'ye entomopatojen fungus içeren biyoinsektisitler $\quad$ (Priority ${ }^{\circledR}$, Nimbecidine ${ }^{\circledR}$, Nostalgist ${ }^{\circledR}$, Bio-Magic ${ }^{\circledR}$ ve Bio-Catch $^{\circledR}$ ) ile bitkisel ekstraktlı bir preparatın (Nimbedicine) laboratuvar koşullarında biyolojik etkinliklerinin belirlenmesidir.

\section{Materyal ve Metot}

Denemenin ana materyalini Şeftali yeşil yaprakbiti olarak bilinen $M$. persicae (Hemiptera: Aphididae), entomopatojen fungus içeren biyoinsektisitler ile bitkisel ekstrakt içeren bir preparat ve negatif karşılaștırma ilacı olarak kullanılan Dursban 4 oluşturmuştur (Tablo 1).

Denemelerde biber bitkisi ve Şeftali yeşil yaprakbiti (M. persicae) üretimine gereksinim duyulmuş olup, $M$. persicae üretimi için Lotus biber çeşidi kullanılmıştır.

Tablo 1. Çalışmada kullanılan preparatlar

\begin{tabular}{|c|c|c|}
\hline Preparatın Adı & Etken Madde & $\begin{array}{l}\text { Etken Madde } \\
\text { Oranı }\end{array}$ \\
\hline Bio-Catch & Verticillium lecanii & $1 \times 10^{9} \mathrm{CFU}$ 's/ml \\
\hline Bio-Magic & $\begin{array}{l}\text { Metarhizium } \\
\text { anisopliae }\end{array}$ & $1 \times 10^{9} \mathrm{CFU}$ 's $/ \mathrm{ml}$ \\
\hline Nostalgist & Beauveria bassiana & $1 \times 10^{8} \mathrm{CFU}$ 's $/ \mathrm{ml}$ \\
\hline Priority & $\begin{array}{l}\text { Paecilomyces } \\
\text { fumosoroseus }\end{array}$ & $1 \times 10^{9} \mathrm{CFU} / \mathrm{s} / \mathrm{ml}$ \\
\hline $\begin{array}{l}\text { Nimbedicine } \\
\text { Dusrban } 4\end{array}$ & $\begin{array}{c}\text { Azadiractin } \\
\text { Chlorpyrifos - ehtyl }\end{array}$ & $\begin{array}{l}3000 \mathrm{ppm} \\
480 \mathrm{~g} / \mathrm{L}\end{array}$ \\
\hline
\end{tabular}

Denemeler laboratuvar ve saksı denemeleri olarak kurulmuş olup, laboratuvar denemelerinde $12 \mathrm{~cm}$ çapındaki plastik petri kapları kullanılmıştır. Petri kaplarının kapaklarına havalandırma delikleri açılmış ve bu delikler ince dokulu tül ile kapatılmıştır. Petri kaplarının alt kısmına nemlendirilmiş pamuk yerleştirilerek. bunun üzerine biber yaprakları aktarılmıştır. Uygulama dozlarında hazırlanan preparatlar el pülverizatörü ile yapraklara, yaprağın tüm yüzeyi islanacak şekilde püskürtülmüştür. $\mathrm{Bu}$ petriler 10 dakika kurumaya bırakıldıktan sonra her bir yaprağın kenarları yaprakbitlerinin kaçmasını önlemek amaciyla Stickem Special isimli özel bir yapıștırıcı ile çevrelenmiştir. Aynı zamanda bu yaprakların su kaybını engellemek için sap kısımlarına nemlendirilmiş pamuk parçaları yerleștirilmiştir. Her petrinin tabanına yerleştirilen pamuklar kurudukça sulanarak ortamın nemli kalması sağlanmıştır. Bu işlemlerden sonra her bir petri kabında bulunan biber yapraklarına, stok kültürden alınan ikinci dönemde bulunan 10'ar adet yaprakbiti bireyleri stereo-binoküler mikroskop yardımı ile aktarılmıştır.

Denemeler tesadüf parselleri deneme desenine göre kurulmuş ve her preparat için 10 tekerrür kullanılmıştır. Hazırlanan tüm petri kapları $25 \pm 1^{\circ} \mathrm{C}$ sıcaklık, \%60 \pm 5 orantılı nem ve 16 saat aydınlık, 8 
saat karanlık ışıklandırma koşullarının sağlandığı iklim odasında muhafaza edilmiştir (Şekil 3.9). Sayımlar uygulamalardan sonra 1., 3., 5. ve 7. günlerinde yapılmış ve sayımlarda canlı ve ölü bireyler dikkate alınmıştır. Kullanılan preparatların konsantrasyonları steril saf su ile seyreltilerek solüsyonlar hazırlanmıștır. Solüsyonlar hazırlanırken ilaçların uygulama dozları dikkate alınmıştır. Kontrol olarak saf su kullanılmıştır.

Laboratuvar denemelerinde kullanılan preparatlar, aynı zamanda saksı denemelerinde de kullanılmıștır. $\mathrm{Bu}$ amaçla fide döneminde satın alınan biber fideleri 6 adet gerçek yapraklı döneme ulaştığında söz konusu preparatlarla tüm bitki tamamen yıkanacak şekilde ilaçlanmıştır. Uygulamalardan 10 dakika sonra her bir bitkinin üç yaprağına, yaprak başına 5 adet yaprakbiti gelecek şekilde, 15'er adet ikinci dönemde bulunan yaprakbitleri ince uçlu firça yardımıyla aktarılmış, böylece her bir uygulama için toplam 60 adet yaprakbiti kullanılmıştır. Yaprakbitlerinin yapraklardan uzaklaşmasını engellemek amacıyla yaprağın sap kısmı StickemSpecial ile çevrelenmiştir. Denemeler dört tekerrürlü olarak kurulmuştur. Bulaşmadan bir hafta sonra her bir bitkideki yaprakbiti bireyleri canlı ve ölü olmak üzere stereo mikroskop altında sayılmıştır. Saksı denemelerinde de kontrol saksılarına saf su uygulanmıştır.

Deneme esnasında ortam koşulları laboratuvar denemelerinde olduğu gibi ayarlanmıştır.

Elde edilen verilere Tek Yönlü Varyans Analizi (ANOVA) uygulanmış ve sonuçların değerlendirilmesinde SPSS (version 17) paket programından yararlanılmıştır. Ortalamalar arasındaki fark Tukey çoklu karşılaştırma testi ile belirlenmiştir.

Sonuçlar ayrıca Abbott formülüne göre de değerlendirilmiştir [32].

\section{Bulgular ve Tartışma}

Petri denemeleri sonucunda Farklı preparatların Myzus persicae'ye etkileri Tablo 2'de verilmiştir.

Çalışmanın yürütüldüğü tüm günlerde kontrol uygulamalarında canlı kalan birey sayıları her zaman en yüksek olarak bulunmuş ve bu değerler istatistik olarak diğer uygulamalardan farklı olmuştur (Tablo 2). Yine tüm günler göz önüne alındığında canlı kalan bireylerin sayları en az Dursban ve Nimbecidine uygulamalarında saptanmış olup bu uygulamalar istatistiki olarak hem kontrolden hem de tüm entomopatojen uygulamalarından farklı bulunmuştur. Entomopatojenlerin etkisi incelendiğinde; genelde canlı kalan ortalama birey sayıları birbirine yakın olmuştur. Sadece 5. günde Nostalgist uygulamasında canlı birey ortalaması diğerlerine göre daha düşük çıkmış olup istatistik olarak da farklı bulunmuştur.

Tablo 2. Farklı preparatların laboratuvar koşullarında Myzus persicae'ye etkileri (Ort. \pm SH)

\begin{tabular}{ccccc}
\hline Preparat & 1. Gün & 3. Gün & 5. Gün & 7 . Gün \\
\hline Kontrol & $9.9 \pm 0.10 \mathrm{a}$ & $9.9 \pm 0.10 \mathrm{a}$ & $9.8 \pm 0.13 \mathrm{a} 9.6 \pm 0.16 \mathrm{a}$ \\
Bio-Catch & $9.3 \pm 0.26 \mathrm{ab}$ & $8.0 \pm 0.21 \mathrm{~b}$ & $6.8 \pm 0.36 \mathrm{bc} 5.9 \pm 0.35 \mathrm{~b}$ \\
Bio-Magic & $9.6 \pm 0.13 \mathrm{ab}$ & $8.4 \pm 0.43 \mathrm{~b}$ & $7.3 \pm 0.21 \mathrm{~b} 6.2 \pm 0.36 \mathrm{~b}$ \\
Nostalgist & $9.4 \pm 0.31 \mathrm{ab}$ & $7.8 \pm 0.39 \mathrm{~b}$ & $5.7 \pm 0.39 \mathrm{c}$ & $5.1 \pm 0.48 \mathrm{~b}$ \\
Priority & $9.5 \pm 0.22 \mathrm{ab}$ & $8.3 \pm 0.26 \mathrm{~b}$ & $7.3 \pm 0.36 \mathrm{~b} 5.9 \pm 0.31 \mathrm{~b}$ \\
Nimbecidine & $8.7 \pm 0.26 \mathrm{~b}$ & $5.8 \pm 0.53 \mathrm{c}$ & $3.4 \pm 0.68 \mathrm{~d} 3.1 \pm 0.65 \mathrm{c}$ \\
Dursban 4 & $0.0 \pm 0.00 \mathrm{c}$ & $0.0 \pm 0.00 \mathrm{~d}$ & $0.0 \pm 0.00$ e $0.0 \pm 0.00 \mathrm{~d}$ \\
\hline * Sütunlar yukaridan aşağıga incelendiğinde aynı harf ile gösterilen \\
ortalamalar Tukey $(\mathrm{P}<0.05)$ testine göre istatistiki olarak farklı değildir.
\end{tabular}

Sonuçlar irdelendiğinde yaprakbitine en etkili preparat olarak geniş spektrumlu bir insektisit olan Dursban 4 saptanmış, bunu bitkisel ekstrakt Nimbecidine izlemiştir. Kontrolden istatistik olarak farklı bir grup oluşturan entomopatojenler ise orta düzeyde bir etki göstermişlerdir (Tablo 2).

$\mathrm{Bu}$ verilerden yola çıkılarak preparatların etki yüzdeleri hesaplanmış ve Şekil 1'de verilmiştir.

Bio-Catch $\square$ Bio-Magic $\square$ Nostalgist $\square$ Priority $\square$ Nimbedicine $\square$ Dusrban 4

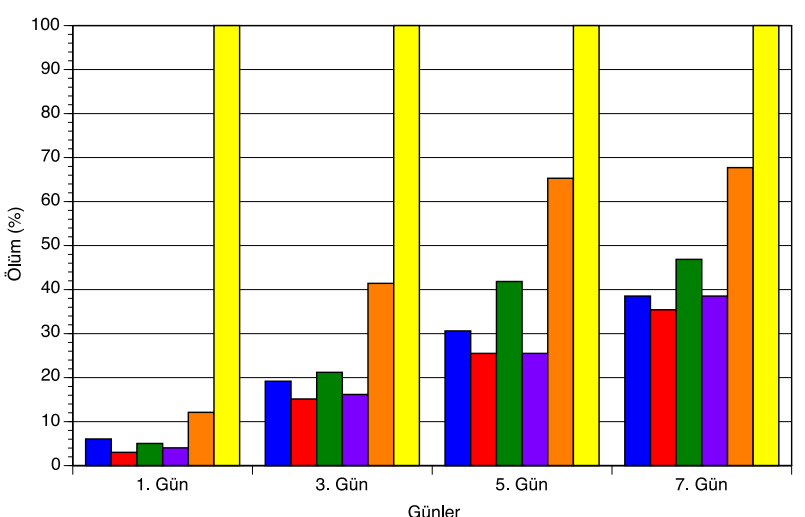

Şekil 1. Myzus persica'ye karşı uygulanan preparatların etki yüzdeleri.

Şekil 1'de izlendiği gibi Dursban 4 hariç diğer preparatların günlere bağlı olarak etkileri giderek artmiştır. Dursban ilk günden itibaren \%100 etki gösterirken, diğer preparatlar göreceli olarak artış göstermiştir.

Preparat etkileri gün bazında ele alındığında belli bir örüntüye sahip olmamışlar, ancak Dursban 4 ve Nimbecidine her aşamada diğerlerine göre daha etkili bulunmuştur. Nostalgist birinci gün hariç diğer günlerde daha etkin bulunurken, Bio-catch her zaman Bio-magicten daha fazla etki göstermiştir.

Zamana bağlı olarak daha ilk günden \%100 ölüm değerine ulaşan Dursban 4 dişında ölüm eğrileri incelendeğinde doğrusal bir ilişki görülmüş ve bu ilişkinin yüzdesi her zaman \%90'ın üzerinde olmuştur (Şekil 2). Ancak entomopatojenlerin ölüm oranları \%50'nin altında kaldığı için LT 50 değerleri hesaplanamamıștır. Nimbecidin de ise populasyonun 
yarısının ölmesi için gereken süreyi belirten $\mathrm{LT}_{50}$ değeri 4.2 gün olarak hesaplanmıştır.

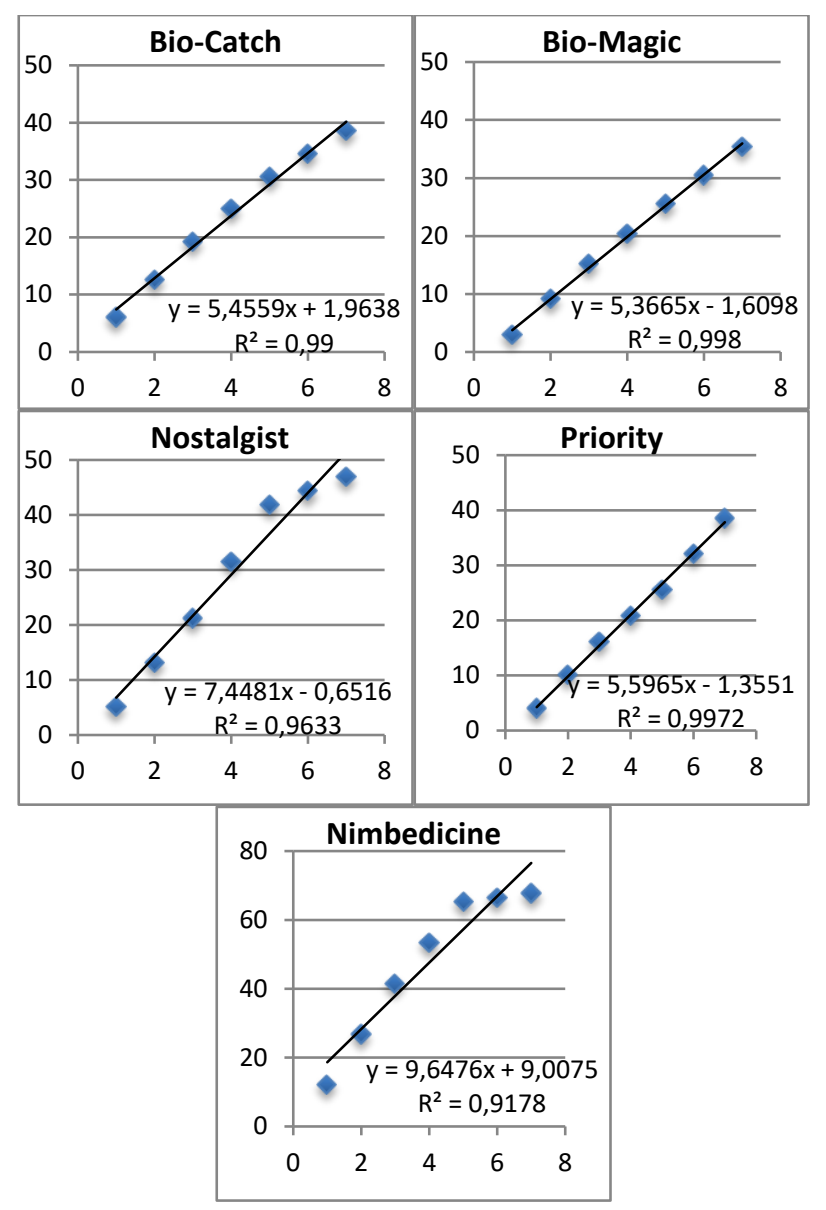

Şekil 2. Zamana bağlı ölüm eğrileri

Bauveria bassiana'nın 10 izolatının Leptinotarsa decemlineata Say. (Coleoptera: Chrysomelidae) ve $M$. persicae ile avcl böcek Coleomegilla maculata lengi Timberlake (Coleoptera: Coccinellidae)'ye etkisinin test edildiği laboratuvar denemelerinde, söz konusu etmenin 6 izolatının ele alınan tüm böceklere oldukça etkili olduğu bulunmuștur [33]. Özellikle M. persicae 'ye üç izolatın etkisi \%100 olurken diğerlerinin etki yüzdeleri farklılk göstermiş olup, 3 izolatın etkisi kontrol ile istatistiki olarak aynı grupta yer almıştır. $\mathrm{Bu}$ çalıșmada ise $B$. bassiana etkili maddeli Nostalgist'in etkisi 7. günde $\% 47$ olmuştur. Literatür çalışmasında da görüldüğü gibi entomopatojen bir türün farklı izolatlarının farklı böceklere karșı etkileri de değișiklikler göstermektedir. Yapılan çalıșmada bildirildiği gibi, farklı entomopatojen fungus türleri ve farklı izolatları, değişik konukçularda patojenisiteleri de farklılık gösterebilmektedir [34]. Aynı araştırıcılar, bir böcek türünün $B$. bassiana'nın bazı izolatlarına dayanıklı gösterirken bazı izolatlarına karşı ise çok hassas olabileceğini ileri sürmektedirler.

Cutler vd. (2009), laboratuvar koşullarında yürüttükleri çalışmalarda, M. persicae'ye karşı bu araştırmada da kullanılan Azadirachtin'in subletal dozlarını (10, 30, 100, 300, $\left.1000 \mu \mathrm{g} \mathrm{L} \mathrm{L}^{-1}\right)$ denemişlerdir. Kontrol denemelerinde su ile birlikte çözücü (Triton) kullanmışlardır. Çalışmada ergin ömrü ve birinci dölde dişi başına yavru sayısı açısından kontrol ve uygulama dozları arasında istatistiki olarak bir fark görülmemiștir. Ancak $F_{1}$ dölündeki nimflerin yaşam süreleri ve $\mathrm{F}_{2}$ dölündeki dişi başına verilen yavru sayılarında farklılık bulunmuştur. $M$. persicae bireyleri F1 dölünde en uzun 4.1 gün ile $30 \mu \mathrm{g} \mathrm{L}^{-1}$ doz uygulamasında, en kısa ise 2.8 gün ile $1000 \mu \mathrm{g} \mathrm{\textrm {L } ^ { - 1 }}$ doz uygulamasında yaşamıştır. F2 dölünde en fazla yavrulama 4.0 ile 30 $\mu \mathrm{g} \mathrm{L}^{-1}$ doz uygulamasinda, en az ise 1.1 ile $1000 \mu \mathrm{g} \mathrm{L}^{-1}$ doz uygulamasında görülmüştür [35].

Saruhan vd., (2015), laboratuvar koşullarında, 20 ve $25{ }^{\circ} \mathrm{C}$ 'de Aphis fabae Scopoli (Hemiptera: Aphididae)'ye karşı bazı entomopatojen fungusların etkisini denedikleri çalışmalarda, burada olduğu gibi entomopatojen olarak ticari preparat Bio-Catch'i, bitkisel ekstrakt olarak Nimbecidine'i kullanmışlardır. Ayrıca bu araștırmada araștırıcıların kendi izolatları olan entomopatojen Lecanicillium muscarium (TR-08) ve Simplicillium lamellicola (TR09)'nın yanında geniş spektrumlu bir insektisit olan Imidacloprid'in de etkisi incelenmiştir [36]. Çalışma sonucunda 7. gün sayımlarında denemeye alınan tüm preparatın etkisinin \%100 olduğu saptanmıştır. Ayrıca Bio-Catch'in $\mathrm{LT}_{50}$ değerinin 20 ve $25{ }^{\circ} \mathrm{C}$ 'de sırasiyla 2.33 ve 2.03 gün, Nimbecidine'in LT50 değerinin 20 ve $25^{\circ} \mathrm{C}^{\prime}$ de sirasiyla 1.46 ve 1.28 gün olduğunu belirlemişlerdir. Mevcut çalıșma ile karşılaştırıldığında 7. günün sonunda hem Nimbecidine'nin etkisi çok yüksek bulunmuş hem de LT50 değeri daha kısa olmuştur. Farklılığın nedeni olarak, ele alınan yaprakbitlerinin türlerinin farklılığından kaynaklanabileceği düşünülmektedir.

Saruhan (2018)'ın yine laboratuvar koşullarında kendi izolatları yanında ticari preparat Nibortem SL, (250 ml/100 l su) (Verticillium lecanii)'i kullanarak yaptıkları çalışmalarda bu preparatın zararlı A. fabae için $\mathrm{LT}_{50}$ değerini, aynı yazarın 2015 yılında yaptığı çalışmadan daha uzun bir süreye denk gelen 4.37 gün olarak saptamışlardır [37]. Bu değer mevcut çalışma ile oldukça benzer bir sonuç vermektedir.

Saksı denemelerinde kullanılan preparatların $M$. persicae'ye yedinci günün sonundaki etkileri Tablo 3'de verilmiștir.

Tablo 3. Saksı denemelerinde kullanılan preparatların Myzus persicae'ye etkileri (Ort. $\pm \mathrm{SH}$ )

\begin{tabular}{cc}
\hline Preparat & 7. Gün Canlı birey sayıları \\
\hline Kontrol & $4.50 \pm 0.23 \mathrm{a}$ \\
Bio-Catch & $2.50 \pm 0.19 \mathrm{bc}$ \\
Bio-Magic & $2.58 \pm 0.22 \mathrm{~b}$ \\
Nostalgist & $2.08 \pm 0.31 \mathrm{bc}$ \\
Priority & $2.83 \pm 0.29 \mathrm{~b}$ \\
Nimbecidine & $1.41 \pm 0.35 \mathrm{c}$ \\
Dursban 4 & $0.0 \pm 0.00 \mathrm{~d}$ \\
\hline *Sütunlar yukarıdan aşağıya incelendiğinde aynı harf ile gösterilen \\
ortalamalar Tukey (P<0.05) testine göre istatistiki olarak farklı değildir.
\end{tabular}

ortalamalar Tukey $(\mathrm{P}<0.05)$ testine göre istatistiki olarak farklı değildir. 
Saksı denemelerinde de tüm preparatların laboratuvar denemelerinde olduğu gibi tüm sayımların yapıldı̆̆ı günlerde kontrolden farklı olduğu ve bu farkın istatistiki olarak da önemli çıktığı görülmektedir (Tablo 3). Yine benzer bir şekilde zararlıya Dursban 4 en etkili olmuş ve bu etki istatistiki olarak da diğer tüm uygulamalardan farklı bulunmuştur. Nimbecidine Dursban 4'den sonra en etkili olmuş ve bu etki diğer biyolojik preparatlara göre farklılık göstermiştir. Bio-Catch ${ }^{\circledR}$, Bio-Magic ${ }^{\circledR}$, Nostalgist ${ }^{\circledR}$ ve Priority ${ }^{\circledR}$ 'nin etkisi birbirine benzer olmuştur.

Söz konusu veriler kullanılarak preparatların \% etkileri hesaplanarak Şekil 3'de verilmiştir.

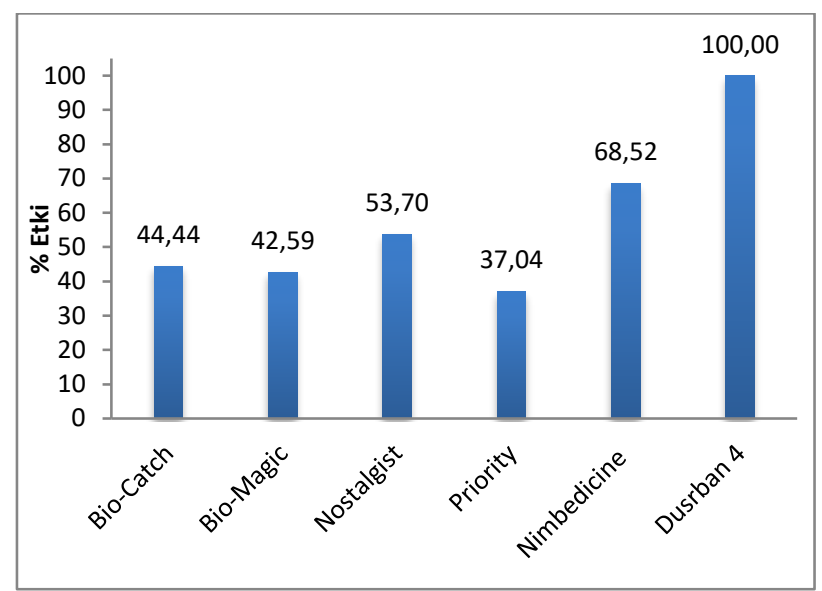

Şekil 3. Preparatların saksı denemelerindeki etkileri (\%).

Şekil 3'de de görüldüğü gibi Dursban 4 tüm yaprakbitlerinin ölümüne neden olarak \%100 etki göstermiştir. Bunu \%68.52 ile bitkisel ekstrakt olan Nimbecidine izlemiştir. Diğer entomopatojen fungusların etkisi ise birbirine benzer olmuştur.

Arazi koşullarında bakla tarlasında yürütülen çalışmalarda, bu araştırmada da denemeye alınan praparatlardan Bio-Catch (Verticillium lecanii), BioMagic (Metarhizium anisopliae), Bio-Power (Beauveria bassiana), Priority (Paecilomyces fumosoroseus) ve Nimbecidine'in börülce yaprakbiti, Aphis craccivora Koch (Hemiptera: Aphididae)'ya etkisi incelemiștir [37]. Bu çalıșmada \%73.3 oranıyla en etkili Bio-Catch (Verticillium lecanii) bulunmuş, bunu \%67.7 ile Nimbecidine izlemiștir. Bio-Magic \%61.6, Priority \%50.3 ve Bio- Power (Beauveria bassiana) ise \%45.5 oranında bir etki göstermişlerdir. Çalışma sonunda yazarlar, Bio-Catch (Verticillium lecanii) ve Nimbecidine'in bakla alanlarında börülce yaprakbiti (A. craccivora)'nin mücadelesinde ümitvar olduğunu belirtmişlerdir. $\mathrm{Bu}$ çalışma ile kıyaslandığında Nimbecidine'in etkisi bir benzerlik gösterirken, diğer kullanılan etmenler literatür çalışmasında daha yüksek etki göstermiştir. $\mathrm{Bu}$ farklılığa ele alınan zararlı türün farklılığı neden olabilir.
Akbar vd. [39], ticari olarak kullanılan iki biyoinsektisit; biosal 10EC (azadirachtin) ve spinosad 240SC ve üç ticari insektisitin (imidacloprid 25WP, endosulfan 35EC ve profenofos 500EC) M. persicae üzerindeki etkilerini denemişler ve bu etkileri sirasıyla $\% 57, \% 15, \% 81, \% 72$ ve $\% 67$ olarak saptamışlardır. $\mathrm{Bu}$ çalışmada denemeye alınan azadirachtin temelli Nimbecidine, literatürde belirlenenden daha fazla oranda bir etkiye (\%68.52) sahip olmuştur.

\section{Sonuç ve Öneriler}

Yürütülen bu çalışmada, biyolojik insektisit BioCatch $^{\circledR}$, Bio-Magic ${ }^{\circledR}$, Nostalgist ${ }^{\circledR}$ ve Priority ${ }^{\circledR}$, bitkisel ekstrakt Nimbecidine ve geniş spektrumlu bir insektisit olan Chlorpyrifos-ethyl etken maddeli Dursban 4'ün $M$. persicae'ye etkileri hem laboratuvarda petri uygulamaları hem de iklim odasında saksı uygulamaları şeklinde denenmiştir.

Her iki uygulama şeklinde de birçok zararlıya karşı tarım alanlarında geniş uygulama alanı bulan Dursban 4 (Chlorpyrifos-ethyl) daha birinci günde tüm popülasyonun ölümüne neden olmuştur. Yine petri ve saksı uygulamalarında bitkisel ekstrakt Nimbecidine yaprakbitine ikinci derecede etki göstermiş olup, bu etki yedinci günde $\% 68.00$ ve 68.52 olarak saptanmıştır. Zararlıya karşı kullanılan biyolojik insektisitlerin (Bio-Catch ${ }^{\circledR}$, Bio-Magic $^{\circledR}$, Nostalgist ${ }^{\circledR}$ ve Priority ${ }^{\circledR}$ ) etkileri yine her iki yöntemde birbirine yakın olarak bulunmuştur. $\mathrm{Bu}$ biyoinsektisitlerin yedinci günde etkileri, petri denemelerinde \%35 ila 47 arasında değişirken, saksı denemelerinde yaklaşık \%37 ila 54 arasında olmuştur.

Bugüne kadar yapılan çalışmalarda Chlorpyrifosethyl'in kalıntı sorunu ve çevre ile balarılarına olumsuz etkileri konusunda birçok çalışma vardır (40 - 45]). Bu çalışmada M. persicae'ye en etkili olarak bulunmakla birlikte, yukarıdaki yazarların da belirttiği gibi çevreye, hedef olmayan organizmalara ve özellikle balarılarına olumsuz etkileri nedeniyle Chlorpyrifos-ethyl'in mümkün olduğunca kullanılmaması gerektiği kanaatine varılmıştır.

$\mathrm{Bu}$ çalışmada zararlıya karşı ikinci derecede etkili bulunan bitkisel ekstrakt Nimbecidine (Azadiractin) ile ilgili olarak yine birçok çalışma bulunmaktadır [38, 46 - 51]. Genel olarak araştırıcılar, neem temelli bitkisel ekstraktların, diğer sentetik pestisitler ile kıyaslandığında çevreye daha az zarar verdiği konusunda ortak düșünceye sahiptir. Bu nedenle bu çalışmada da etkili bulunan Nimbecidine'in $M$. persicae'ye karşı güvenle kullanılabileceği görüşü oluşmuştur.

Diğer entomopatojenlerin $M$. persicae'ye etkileri gerek kimyasal, gerekse bitki ekstraktına göre düşük olmuş ve bu etki hem petri denemelerinde hem de saksı denemelerinde genellikle \%50'nin altında 
kalmıştır. Bugüne kadar M. persicae ile ilgili yapılan çalışmalara bakıldı̆̆ında; [52], iki entomopatojen fungus (Pandora delphacis ve P. neoaphidis)'un farklı dozlarının zararlı üzerinde \%31.7 ila \%93.8 arasında değiştiğini, [33], B. bassiana'nın 10 izolatının $M$. persicae'ye etkilerinin yaklaşık \%40 ila 100 arasında değiștiğini, [53], entomopatojen funguslardan Lecanicillium lecanii, Paecilomyces farinosus, Beauveria bassiana, Metarhizium anisopliae, Cordyceps scarabaeicola ve Nomuraea rileyi'nin 12 izolatını denedikleri laboratuvar çalışmalarında, $L$. lecanii'nin 41185'nolu izolatının M. persicae'ye etkilerinin beșinci günde \%100'e ulaștığını, [54], entomopatojen Lecanicillium longisporum'un $M$. persicae'ye \%56 oranında etkili olduğunu, [55], $B$. bassiana ve $V$. lecanii'nin üçer izolatını denedikleri çalışmalarda bunların etkilerinin \%60.17 ila 88.36 arasında saptandığını bildirmektedirler. Bu çalışmada ele alınan entomopatojenlerin $M$. persicae'ye etkileri çok yüksek olmamakla birlikte entegre mücadele çalışmalarında destekleyici etmenler olarak kullanılabileceği söylenebilir.

\section{Kaynakça}

[1] Remaudiere, G., Remaudiere, M. 1997. Catologue des Aphididae du Monde (Of the World's Aphididae) Homoptera, Aphidoidea, Preface Par V.F. Eastop, INRA Editions, 473 pp.

[2] Düzgünes, Z., Tuatay, N., 1956. Türkiye Aphid'leri. Ankara Ziraat Mücadele Enstitüsü Müdürlügü Sayı, 4: 1-63.

[3] Bodenheimer, F.S., Swirski, E., 1957. The Aphidoidea of the Middle East. Weizmann Science Press of Israel, Jerusalem, $378 \mathrm{pp}$.

[4] Tuatay, N., Remaudière, G., 1964. Première contribution au catalogue des Aphididae (Hom.) de la Turquie. Revue de Pathologie Végétale et d' Entomologie Agricole de France, 43: 243-278.

[5] Giray, H., 1974. İzmir ili çevresinde Aphididae (Homoptera) familyası türlerine ait ilk liste ile bunların konukçu ve zarar şekilleri hakkında notlar. Ege Üniversitesi Ziraat Fakültesi Dergisi, 11 (1), 39-69.

[6] Çanakçığlu, H., 1966. Türkiye'de orman ağaçlarına arız olan bitki bitleri (Aphidoidea) üzerinde araştırmalar. İstanbul Üniversitesi Orman Fakültesi Dergisi, 16(2), 131-190.

[7] Çanakçıoğlu, H., 1975. The Aphidoidea of Turkey. İstanbul Üniversitesi Orman Fakültesi Yayınları. Yayın No: 189, 309 s.

[8] Tuatay, N., 1988. Türkiye yaprakbitleri (Homoptera: Aphididae) I. Aphidinae Macropsophini (I. Kısım). Bitki Koruma Bülteni, 28 (1-2), 1-28.

[9] Tuatay, N., 1990. Türkiye yaprakbitleri (Homoptera: Aphididae) II. Aphidinae Macropsophini (II. Kısım). Bitki Koruma Bülteni,
30 (1-4), 29-44.

[10] Tuatay, N., 1991. Türkiye yaprakbitleri (Homoptera: Aphididae) III. Aphidinae: Macropsophini (III. Kısım). Bitki Koruma Bülteni, 31 (1-4), 3-18.

[11] Tuatay, N., 1993. Türkiye yaprakbitleri (Homoptera: Aphididae) IV. Aphidinae: Aphidini (I. Kısım). Bitki Koruma Bülteni, 33 (3-4), 83106.

[12] Tuatay, N., 1993. Aphids of Turkey (Homoptera: Aphididae) IV. Aphidinae: Macrosiphini Part IV. Bulletin of Plant Protection, 33 (1-2), 83-105.

[13] Tuatay, N., 1999. Türkiye yaprakbitleri (Homoptera: Aphididae): V. Chaitophinae, Lachninae ve Thelaxinae. Bitki Koruma Bülteni, 39 (1-2), 1-21.

[14] Toros, S., Uygun, N., Ulusoy, R., Satar, S., Özdemir, I., 2002. Doğu Akdeniz Bölgesi Aphidoidea Türleri. Tarım ve Köyişleri Bakanlığı Tarımsal Araştırmalar Genel Müdürlüğü, Ankara. 108 s.

[15] Görür, G., 2004. Aphid (Homoptera: Aphididae) species on pome fruit trees in Nigde Province of Turkey. Turkiye Entomoloji Dergisi, 28(1), 2126.

[16] Uysal, M., Şahbaz, A., Özdemir, I., 2006. Konya ilinde kavaklarda beslenen yaprakbiti (Homoptera: Aphididae) türleri. Selçuk Üniversitesi Ziraat Fakültesi Dergisi, 20(38), 143-149.

[17] Ayyıldız, Y., Atlıhan, R., 2006. Balıkesir ili sebze alanlarında g.rülen yaprakbiti türleri ve doğal düşmanları. Yüzüncü Yıl Üniversitesi Ziraat Fakültesi Tarım Bilimleri Dergisi, 16(1), 1-5.

[18] Barjadze, S., Özdemir, I., Blackman, R., 2014. Two new species of Aphidini Latreille, 1802 (Hemiptera: Aphididae) from Turkey. Zootaxa, 3873 (2), 197-194.

[19] Barjadze, S., Japoshvili, G., Karaca, İ. Özdemir, I., 2014. Aphids (Hemiptera: Aphidoidea) of Gölcük Natural Park (Isparta Province, Turkey). Munis Entomology \& Zoology Journal, 9 (1): 206-213.

[20] Görür, G., Şenol, O., Gezici, G., Akyıldırım-Beğen, H., Parmaksiz, D., 2012. New aphid (Hemiptera: Aphidoidea) records from South Eastern Parts of Turkey. Journal of Insect Biodiversity and Systematics, 03 (3), 257-264.

[21] Avidov, Z., Harpaz, I., 1969. Plant Pests of Israel. Israel Univ. Press, Jerussalem, $549 \mathrm{pp}$.

[22] Kennedy, J.S., Day, M.F., Eastop, V.F., 1962. A Conspectus of Aphids as Vector of Plant Viruses Commonwealth. Inst. Ent., 114 p, London, England.

[23] Blackman, R.L., Eastop, V.F., 2000. Aphids on The World's Crops: An Identification quide. Second Edition. A Wiley. The Natural History Museum Intenscience Publication, London, England, 414 
pp.

[24] Kocadal, E., 2006. Kuzey Kıbrıs Türk Cumhuriyeti'ndeki Aphidoidea (Homoptera) Türleri, Bunların Konukçuları, Parazitoit ve Predatörlerinin Belirlenmesi. (Yüksek Lisans Tezi), Çukurova Üniversitesi Fen Bilimleri Enstitüsü Bitki Koruma Anabilim Dalı, Adana.

[25] Boukhris-Bouhachem, S., Souissi, R., Turpeau, E., Rouzé-Jouan, J., Fahem, M., Brahim, N.B., Hullé, M., 2007. Aphid Diversity in Tunisia in Relation to Seed Potato Production. Annales de la Société Entomologique de France (N.S.), 43 (3), 311318.

[26] Szpeiner, A. 2008. Aphididae (Hemiptera) on Ornamental Plants in Córdoba (Argentina). A Revista de la Sociedad Entomologica Argentina, 67 (1-2), 49-56.

[27] Velioğlu, A.S., Toros, S., 2002. Değişik Bölgelerden Toplanan Myzus persicae (Sulz.) (Hom.: Aphididae) Populasyonlarının Bazı İnsektisitlere Karşı Dayanıklılık Düzeylerinin Araştırılması. Bitki Koruma Bülteni, 42(1-4), 6779.

[28] Vučetić, $\quad$ A., $\quad$ Petrović-Obradović, $\quad 0$. , margoritopoulos, J., Skouras, P., 2008. Establishing the resistance of Myzus persicae (Sulzer) by molecular methods. Arch. Biol. Sci., Belgrade, 60 (3), 493-499.

[29] Akbar, M.F., Haq, M.A., Parveen, F., Yasmin, N., Khan, M.F.U. 2010. Comparative management of cabbage aphid (Myzus persicae (Sulzer) (Aphididae: Hemiptera) through bio and synthetic insecticides. Pakistan Entomologist, $32,12-17$

[30] Erkılıç, L. ve Uygun, N., 1993. Entomopatojen Fungusların Biyolojik Mücadelede Kullanılma Olanakları. Türkiye Entomoloji Dergisi, 17, 217128.

[31] Mahr, S.E.R., Cloyd, R.A., Mahr, D.L., Sadof, C.S., 2001. Biological control of insects and other pests of greenhouse crops. North Central Regional Publication, 581, 102 pp.

[32] Abbott, W.S., 1925. A Method of Computing the Effectiveness of an Insecticide. Journal of Economic Entomology, 18, 265-267.

[33] Todorova, S.I., Coderre, D., Côté, J.C., 2000. Pathogenicity of Beauveria bassiana Isolates Toward Leptinotarsa decemlineata [Coleoptera: Chrysomelidae], Myzus persicae [Homoptera: Aphididae] and Their Predator Coleomegilla maculata lengi [Coleoptera: Coccinellidae]. Phytoprotection, 81(1), 15-22.

[34] Butt, T.M., İbrahim, L., Bail, B.V., Clark, S.J., 1994. Pathogenicity of the Entomogenous Fungi Metarhizium anisopliae and Beauveria bassiana Against Crucifer Pests and The Honey Bee. Biocontrol Science and Technology, 4, 207-214.
[35] Cutler, G.C., Ramanaidu, K., Astatkie, T., Isman, M.B., 2009. Green peach aphid, Myzus persicae (Hemiptera: Aphididae), reproduction during exposure to sublethal concentrations of imidacloprid and azadirachtin. Pest Manag Sci, 65:205-209.

[36] Saruhan, I., Erper, I., Tuncer, C., Akca, I., 2015. Efficiency of Some Entomopathogenic Fungi as Biocontrol Agents Against Aphis fabae Scopoli (Hemiptera: Aphididae). Pakistan Journal of Agricultural Sciences, 52, 273-278.

[37] Saruhan, I., 2018. Efficacy of some entomopathogenic fungi against Aphis fabae Scopoli (Hemiptera: Aphididae). Egyptian Journal of Biological Pest Control. 28:89.

[38] El-Salam, A.A., Salem, S.A., El-Kholy, M.Y., 2012. Efficiency of Nimbecidine and Certain Entomopathogenic Fungi Formulations Against Bean Aphids, Aphis Craccivora in Broad Bean field. Archives of Phytopathology and Plant Protection, 45(19), 2272-2277.

[39] Akbar, M.F., Rana, H.U., Parveen, F., 2014. Management of Cauliflower Aphid (Myzus Persicae (Sulzer) Aphididae: Hemiptera) Through Environment Friendly Bioinsecticides. Pak. Entomol., 36(1), 25-30.

[40] Ay, R., Karaca, İ., Seçilmiş, H., 2003. Isparta İlinde Elma Bahçelerinde Yaygın Kullanılan Chlorpyrifos ve Diazinon'un Kalıntı Düzeylerinin HPLC ile Belirlenmesi. Türkiye Entomoloji Dergisi, 27(4), 293-304.

[41] Solomon, K.R., Williams, W.M., Mackay, D., Purdy, J., Giddings J.M., Giesy, J.P., 2014. Properties and Uses of Chlorpyrifos in The United States. Egyptian Journal of Biological Pest Control, 231, 13-34.

[42] Cutler, G. C., Purdy, J., Giesy, J.P., Solomon, K.R., 2014. Risk to Pollinators from The Use of Chlorpyrifos in The United States. J.P. Giesy and K.R. Solomon (Ed.), Ecological Risk Assessment for Chlorpyrifos in Terrestrial and Aquatic Systems in the United States, Reviews of Environmental Contamination and Toxicology 231, 219-265.

[43] Mackay, D., Giesy, J.P., Solomon, K.R., 2014. Fate in The Environment and Long-Range Atmospheric Transport of The Organophosphorus Insecticide, Chlorpyrifos and Its Oxon. Reviews of Environmental Contamination and Toxicology, 231, 35-76.

[44] Tong, Z., Duan, J., Wu, Y., Liu, Q., He, Q., Shi, Y., Cao, H., 2018. A Survey of Multiple Pesticide Residues in Pollen and Beebread Collected in China. Science of The Total Environment, 640, 1578-1586.

[45] Karahan, A., Kutlu, M.A., Gül, A., Karaca, İ., 2018. The Effect of Pesticides on Honey Bees. 6th 
International Muğla Beekeeping and Pine Honey Congress, 15-19 October, Muğla, 84-90.

[46] Singh, K., Singh, A., Singh, D.K., 1996. Molluscicidal Activity of Neem (Azadirachta indica A. Juss). Journal of Ethnopharmacology, 52(1), 35-40.

[47] Mondal D., Barat, S., Mukhopadhyay, M.K., 2007. Toxicity of Neem Pesticides on a Fresh Water Loach, Lepidocephalichthys guntea (Hamilton Buchanan) of Darjeeling District in West Bengal. Journal of Environmental Biology. 28(1), 119122.

[48] Murugesan, N., Murugesh, T., 2009. Bioefficacy of Some Plant Products Against Brinjal Fruit Borer, Leucinodes orbonalis Guenee (Lepidoptera: Pyrallidae). Journal of Biopesticides, 2(1), 60-63.

[49] Singh, P.K., Ansari, B.A., 2010. Effect of NeemBased Formulations (Nimbecidine and Ultineem) on the Sparing Success of Zebrafish Danio rerio (Cyprinidae). Bioscan, 5, 669-672.

[50] Shoaib, M.A., Mahmoud, M.F., Loutfy, N, Tawfic, M.A., Barta, M., 2010. Effect of Botanical Insecticide Nimbecidine $\AA$ on Food Consumption and Egg Hatchability of the Terrestrial Snail Monacha obstructa. J Pest Sci (2010) 83:27-32.

[51] Bhardwaj, A.K., Ansari, B.A., 2015. Effect of
Nimbecidine and Neemazal on the Developmental Programming of Cotton Pest, Earias vittella. Journal of Entomology and Zoology Studies, 3(1), 38-42.

[52] Xu, J.H., Feng, M.G., 2000. The Time-DoseMortality Modeling and Virulence Indices for Two Entomophthoralean Species, Pandora delphacis and P. neoaphidis, Against the Green Peach Aphid, Myzus persicae. Biological Control, 17(1), 29-34.

[53] Vu, V.H., Hong, S.I,, Kim, K., 2007. Selection of Entomopathogenic Fungi for Aphid Control. Journal of Bioscience and Bioengineering, 104(6), 498-505.

[54] Down, R.E., Cuthbertson, A.G., Mathers, J.J., Walters, K.F., 2009. Dissemination of the Entomopathogenic Fungi, Lecanicillium longisporum and L. muscarium, by The Predatory Bug, Orius laevigatus, To Provide Concurrent Control of Myzus persicae, Frankliniella occidentalis and Bemisia tabaci. Biological Control, 50(2), 172-178.

[55] Khan, M., Khalil, S.K., 1990. Biological Control of Aphid With an Entomopathogenic Fungus. Pakistan Journal of Agricultural Research, 11(3), 174-177. 